\title{
MANAJEMEN PEMBELAJARAN SENTRA ALAM PADA ANAK USIA DINI DALAM MENINGKATKAN KECERDASAN KONGNITIF ANAK
}

\author{
Nur Tamami ${ }^{*}$, Indi Aunullah ${ }^{2}$, Faizatul Widat ${ }^{1}$, Rosita Wahyu Rani $^{1}$ \\ ${ }^{1}$ Universitas Nurul Jadid, Probolinggo, East Java, Indonesia \\ ${ }^{2}$ Sekolah Tinggi Agama Islam Nurul Abror Al Robbaniyin, Banyuwangi, East Java, Indonesia
}

DOI: https://doi.org/10.52627/ijeam.v3i2.94

Article History:

Received: July 2021

Accepted: July2021

Published: August 2021

\section{Keywords:}

Manajemen, Pembelajaran Sentra, Kecerdasan Kongnitif

*Correspondence Address: stnurtamami@gmail.com

\section{Abstract :}

This study aims to understand and analyze the management of natural center learning in early childhood in improving children's cognitive intelligence in Raudlatul Athfal Zainul Hasan, Tambelang Village, Krucil District, Probolinggo Regency. This research uses a qualitative type of case study. Data collection techniques are carried out through interviews, observation and documentation. The data analysis was carried out in a circular manner, starting from the data display, followed by drawing conclusions. The results showed that the learning management of natural centers in improving students' cognitive intelligence was carried out through planned and systematic planning by the teacher with reference to policies that have been determined by the government and existing local policies, followed by implementation of learning activities that try to bring students to the real world and ends with an evaluation based on authentic assessment.

\footnotetext{
Abstrak :

Penelitian ini bertujuan untuk memahami dan menganalisis tentang manajemen pembelajaran sentra alam pada anak usia dini dalam meningkatkan kecerdasan kongnitif anak di Raudlatul Athfal Zainul Hasan, Desa Tambelang, Kecamatan Krucil, Kabupaten Probolinggo. Penelitian ini menggunakan kualitatif jenis studi kasus. Teknik pengumpulan datanya dilakukan melalui interview, observasi dan dokumentasi. Analisis datanya dilakukan secara sirkuler, yang dimulai dari data display, dilanjutkan dengan penarikan kesimpulan. Hasil penelitian menunjukkan bahwa manajemen pembelajaran sentra alam dalam meningkatkan kecerdasan kognitif siswa dilakukan melalui perencanaan secara terencana dan sistematis oleh guru dengan mengacu pada kebijakan yang telah ditentukan oleh pemerintah dan kebijakan lokal yang ada, dilanjutkan dengan pelaksanaan pada kegiatan pembelajaran yang berusaha membawa siswa pada alam nyata dan diakhiri dengan evaluasi berbasis authentic assesment.
} 


\section{PENDAHULUAN}

Banyak cara yang dilakukan oleh seorang pendidik untuk membantu anak didiknya mengembangkan seluruh potensinya (Alfina \& Anwar, 2020). Setiap pendidik memiliki cara tersendiri untuk membantu menstimulasi setiap aspek perkembangan anak didiknya (Iltiqoiyah, 2020). Cara yang dilakukan bisa saja berbeda atau sama untuk setiap aspek perkembangan dan setiap anak bisa saja mendapatkan stimulasi yang sama atau berbeda untuk setiap aspek perkembangannya (Tatminingsih, 2019; Nurmiyanti \& Candra, 2019).

Salah satu kegiatan pengembangan kognitif yang harus dicapai adalah anak mampu memahami berbagai konsep sederhana dalam kehidupan seharihari termasuk kemampuan memahami konsep ukuran. Hal ini diperkuat Yuniarni (2014) bahwa anak usia dini perlu dikenalkan dengan konsep ukuran dengan tujuan anak dapat menyelesaikan masalah yang terjadi dalam kehidupan sehari-hari (Maratus, 2016).

Pendidikan pada dasarnya merupakan usaha kebudayaan dengan maksud memperluas kualitas hidup dan kehidupan manusia baik secara individual, kelompok masyarakat maupun sebagai suatu bangsa (Atika et al., 2021). Pendidikan dan pengajaran bukan hanya menenuhi otak anak dengan ilmu, tetapi juga mendidik jiwanya dengan menanamkan rasa keutamaan (fadhilah), membiasakan beradab sopan santun dan mengarahkan untuk kehidupan yang bermakna (Purnomo et al., 2021). Keutamaan pendidikan akhlak dan tingkah laku, merupakan salah satu pancaran keimanan yang telah meresap ke dalam kehidupan keberagamaannya (Arif \& Pratama, 2019; Almuhajir, 2021).

Sebagian besar anak yang berusia 4-5 tahun (kelompok A) di sekolah sudah bisa bertanggung jawab mengembalikan sesuatu sesuai dengan tempatnya, memiliki sikap taat pada aturan dan waktu yang telah di sepakati, memiliki kemandirian dalam memilih kegiatan dan menyelesaikan tugas sampai selesai (Qori'ah, 2019).

Seiring berjalannya waktu, semakin disadari bahwa penggunakan teknologi seperti komputer, alat komunikasi, dan sejenisnya perlu dikenalkan kepada anak-anak sejak usia dini. Beberapa sekolah RA telah memiliki program ekstrakurikuler komputer untuk anak usia dini, yang mana pelaksanaannya di akhir pekan dan diagendakan sekali dalam seminggu (Zuarida, 2020).

Pembelajaran sentra adalah salah satu dari beberapa model pembelajaran di RA yang dapat dilaksanakan untuk meningkatkan kemampuan dasar anak, khususnya kognitif, model pembelajaran sentra dapat kita modifikasikan agar lebih menarik, di mana anak dan guru berada dalam satu lingkaran agar tidak ada batasan antara keduanya sehingga anak belajar dengan nyaman dan gembira (happy learning) (Erwani, 2017).

Kesadaran para orang tua akan arti pentingnya pendidikan anak usia dini pada saat ini meningkat seiring dengan bertambahnya jumlah lembaga penyelengara PAUD yang terus bertambah di wilayah-wilayah seluruh Indonesia Pendidikan anak usia dini adalah upaya pembinanaan yang ditujukan kepada anak sejak lahir sampai dengan usia enam tahun yang dilakukan melalui pemberian rangsangan pendidikan untuk membantu 
perkembangan jasmani dan rohani agar anak kelak memiliki kesiapan dalam memasuki pendidikan lebih lanjut hal ini bisa dilihat dari (Watini, 2019).

Kemampuan berbicara pada anak merupakan suatu kemampuan untuk berkomunikasi dengan orang lain, dimana pikiran dan perasaan individu dinyatakan dalam bentuk lambang atau simbol seperti lisan,tulisan, isyarat, bilangan, lukisan, maupunmimik yang digunakan untuk mengungkapkan sesuatu kepada orang lain (Alfatihaturrohmah et al., 2018).

Para pendidik memiliki peran sentral sebagai motivator, fasilitator, mentor/penasehat yang dapat membantu anak dalam mengembangkan potensi dan minat pada bidang yang digemarinya. Penguasaan keterampilan motorik juga dapat memacu anak untuk menekuni bidang tertentu sejak dini seperti bermain melukis, musik, membuat kerajinan, membuat gambar desain, dan lain sebagainya (Widayati et al., 2018).

Dengan demikian model pembelajaran sentra dapat kita terapkan pada lembaga dengan proses pembelajaran dilakukan di dalam lingkaran circle time dan sentra bermain. Lingkaran adalah dimana pendidik duduk bersama anak dengan posisi melingkar untuk memberikan pijakan kepada anak yang dilakukan sebelum dan sesudah bermain contoh pembelajaran sentra, sentra balok, sentra main peran kecil dll.

Peran pendidik dan karakteristik pendidik saling berhubungan meskipun tidak secara langsung. Seorang anak memulai proses belajar sejak menit-menit pertama dalam hidupnya. anak atau peserta didik berhak mendapatkan pelayanan yang bermakna (meaningful), seperti lingkungan yang bermanfaat untuk proses belajarnya (Mundiri \& Adhimiy, 2019).

Model sentra berfungsi sebagai wadah kegiatan bermain anak yang memberikan kesempatan untuk dapat mengembangkan kemampuan dan keterampilan anak melalui bermain tanpa tekanan dan paksaan dari guru dan lingkungannya. Selain itu model pembelajaran sentra memiliki ciri khusus yang membedakan dengan model kelompok, area maupun sentra (Nurhasanudin \& Santika, 2021).

Salah satu contoh yang dapat dilakukan pendidik adalah dengan belajar sentra bahan alam. Guru memilih model pembelajaran sentra bahan alam dianggap relevan dalam memfasilitasi anak untuk mengembangkan dan memperluas pengalaman bermain sensorimotor dengan mengeksplorasi bahanbahan alami (daun, ranting, kayu, biji-bijian, air, pasir, batu, dan lain-lainnya), sehingga dapat mengembangkan motorik halus anak (Sutisnawati et al., 2020)

Konsep ini menjadi salah satu akar munculnya konsep pendidikan yang berbasis pada alam atau back to nature school. Ide dasarnya adalah pendidikan pada anak dilakukan dengan mengajak anak dalam suasana sesungguhnya melalui belajar pada lingkungan alam sekitar yang nyata. Bentuk pengajaran ini dilakukan sebagai upaya menentang bentuk pengajaran yang cenderung intelektualisme dan verbalistik (Sunanik, 2018).

Pendidikan adalah hak asasi semua manusia oleh sebab itu pendidikan harus dapat dinikmati oleh semua warga negara Indonesia termasuk juga anak pada usia dini atau anak pada usia pra sekolah. Begitu pentingnya pendidikan bagi setiap manusia, karena tanpa adanya pendidikan sangat mustahil suatu 
komunitas manusia dapat hidup berkembang sejalan dengan cita-citanya untuk maju, mengalami perubahan, sejahtera dan bahagia sebagaimana pandangan hidup mereka (Fatmawati, 2019).

Di dalam model pembelajaran sentra dilengkapi 3 jenis kegiatan main yaitu bermain sensorimotorik, main peran dan main pembangunan. Keragaman main pada sentra disebut juga densitas main yang memfasilitasi anak untuk dapat memilih mainan sesuai dengan minatnya. Dalam sentra setiap kelas akan berpindah bermain dari satu sentra kesentra lainnya setiap hari. Setiap sentra dikelola seorang guru. Proses pembelajarannya dengan menggunakan 4 pijakan yaitu pijakan penataan alat (pijakan lingkungan), pijakan sebelum main, pijakan selama main, dan pijakan setelah bermain.

Model pembelajaran sentra adalah pendekatan pembelajaran yang dalam proses pembelajarannya dilakukan di dalam 'lingkaran' (circle time) dan sentra bermain. Lingkaran adalah saat dimana guru duduk bersama anak dengan posisi melingkar untuk memberikan pijakan sebelum dan sesudah bermain. Sentra bermain merupakan zona atau area dengan seperangkat sebagai pijakan lingkungan yang diperlukan untuk mengembangkan seluruh potensi dasar anak didik dalam berbagai aspek perkembangan secara seimbang, serba seimbang. Sentra dibuka setiap harinya disesuaikan dengan jumlah kelas.

Pembelajaran yang berpusat pada sentra dilakukan secara tuntas mulai awal kegiatan sampai akhir dan fokus oleh satu kelompok usia dalam satu sentra kegiatan. Setiap sentra mendukung perkembangan anak dalam tiga jenis bermain yaitu bermain sensorimotor atau fungsional, bermain peran dan bermain konstruktif (membangun pemikiran anak). Berangkat dari hal tersebut, maka focus penelitian ini adalah bagaiamana manajemen pembelajaran sentra alam pada anak usia dini dalam meningkatkan kecerdasan kongnitif anak di Raudlatul Athfal Zainul Hasan, Kecamatan Krucil, Kabupaten Probolinggo ?.

\section{METODE PENELITIAN}

Penelitian ini menggunakan pendekatan kualitatif jenis studi kasus, di mana peneliti berusaha untuk memahami dan menganalisis tentang manajemen pembelajaran sentra alam pada anak usia dini dalam meningkatkan kecerdasan kongnitif anak di Raudlatul Athfal Zainul Hasan, Kecamatan Krucil, Kabupaten Probolinggo, Jawa Timur. Untuk mendapatkan data yang dapat dipertanggung jawabkan, peneliti melakukan observasi terhadap berbagai kegiatan pembelajaran yang dilakukan oleh guru dengan menggunakan pendekatan sentra alam guna meningkatkan kecerdasan kognitif siswa. Interview dilakukan kepada kepala sekolah dan beberapa guru. Dokumentasi dijadikan sebagai media untuk memperkuat data penelitian. Analisis datanya dilakukan secara sirkuler, yang dimulai dari data display, dilanjutkan dengan penarikan kesimpulan 


\section{HASIL DAN PEMBAHASAN}

\section{Perencanaan model pembelajaran sentra alam}

Hasil penelitian menunjukkan bahwa; strategi guru dalam meningkatkan kecerdasan kognitif anak usia dini melalui model pembelajaran sentra alam di Raudlatul Athfal Zainul Hasan, dapat digambarkan sebagai berikut;

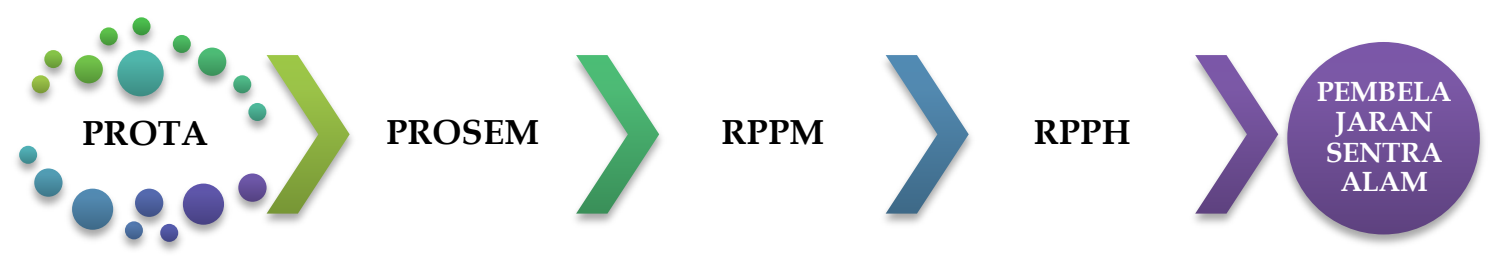

\section{Gambar 1 : Perencanaan Pembelajaran Sentra Alam}

Dalam menentukan pembelajaran sentra alam, guru terlebih dahulu membuat Program Tahunan (PROTA) untuk menetukan garis-garis besar yang hendak dicapai dalam satu tahun yang dikembangkan oleh guru. Hal ini sebagaimana disampaikan oleh Siti Rahayu "saya disuruh oleh kepala sekolah untuk menyusun prota menjadi pedoman bagi pengembangan programprogram berikutnya seperti program semester, rencana mingguan, rencana harian, juga sistem penilaian pembelajaran. Prota tersebut memberikan petunjuk kemudahan dalam kegiatan pembelajaran".

Selanjutnya guru membuat program semester (PROSEM) untuk menentukan rumusan pokok-pokok aktivitas guru dalam melakukan pembelajaran selama satu semester dengan mempertimbangkan alokasi waktu yang tersedia jumlah kompetensi dasar dan indikator. Hal ini sebagaimana disampaikan oleh Nur Hayati selaku guru di lembaga tersebut bahwa "program semester dibuat dengan mengacu pada prota agar supaya pelaksanaan pembelajaran dapat berjalan efektif dan efisien".

Rencana Program Pembelajaran Mingguan (RPPM) dibuat guru untuk menentukan rencana taktis guna menentukan pembelajaran selama satu minggu yang berisi identitas program layanan, Kompetensi Dasar yang dipilih, materi pembelajaran dan rencana kegiatan. Hal ini sebagaimana disampaikan oleh Sri Nanik yang mengatakan bahwa RPPH yang dibuata oleh guru menjadi acuan dalam melaksanakan kegiatan pembelajaran, sehingga guru dapat dengan mudah menentukan target yang akan dicapai.

Langkah terakhir adalah pembuatan Rencana Program Pembelajaran Harian (RPPH) sebagai acuan guru dalam mengajar dan bertatap muka dengan siswa. Dalam hal ini RPPH dibuat dengan pendekatan pembelajaran sentra alam. Hal ini sebagaimana disampaikan oleh Siti Rahayu yang mengatakan bahwa sebelum kegiatan belajar mengajar dimulai, guru menyiapkan rencana kegiatan pembelajaran yang mengacu pada program tahunan, program semester, rencana pelaksanaan pembelajaran mingguan, dan Rencana pelaksanaan pembelajaran harian sesuai kurikulum jenjang RA. Guru juga mempersiapkan penyajian dan penyampaian bahan belajar untuk wali murid. 


\section{Implementasi Sentra}

Setelah guru mendesain pembelajaranya maka kemudian guru menerapkan apa yang dituangkanya dalam RPPH, dengan mengacu pada model pembelajaran sentra, guna meningkatkan kecerdasan kognitif anak dalam praktek di lapangan.

Pertama guru menyiapkan media belajar untuk pembelajaran di luar ruangan seperti gunting, lem, kertas dan lain sebagainya. Seperti halnya penuturan dari ibu Sri Nanik yang mengatakan bahwa guru membentuk kelompok, antara empat atau lima anak dalam satu kelompok, setelah itu guru menyuruh anak membuat lingkaran pada kelompok tersebut dengan tiga kelompok didampingi satu guru.

Pembelajaran sentra alam ditunjukkan pada kegiatan guru mengajak siswa bermain di alam bebas, hal ini sesusai dengan observasi di lapangan, sebagaimana gambar berikut

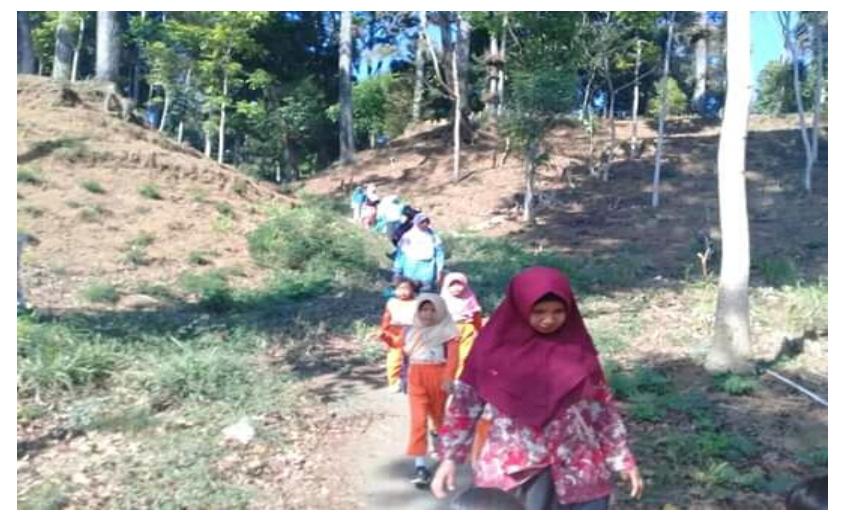

\section{Gambar 1: Pembelajaran Sentra Alam}

Mengajak anak berjalan kaki menuju tempat lokasi pembelajaran sentra alam, dan mengenalkan beberapa tanaman yang dilihat di samping kanan kirinya sambil bernyanyi tema alam, seperti dalam gambar berikut;

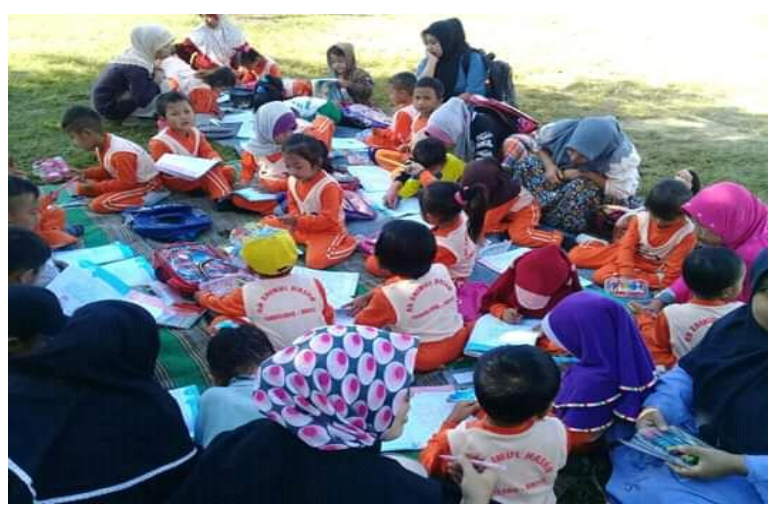

Gambar 1: Kegiatan Pembelajaran di Alam

Menyuruh anak mengumpulkan bahan-bahan yang akan digunakan untuk menempel gambar yang sudah dipersiapkan oleh gurunya. Kemudian guru menyuruh anak untuk mencari bahan dasar yang ada di sekitar mereka untuk dijadikan sebagai bahan materi ajar. Setelah bahan dasr tersebut 
terkumpul dengan baik, maka guru mengajak anak-anak untuk menempel benda tersebut ke dalam bidang kertas yang telah disiapkan oleh guru. Gambar berikut menunjukkan aktivitas pembelajan yang dilakukan secara bersamasama, antara guru dan siswa.
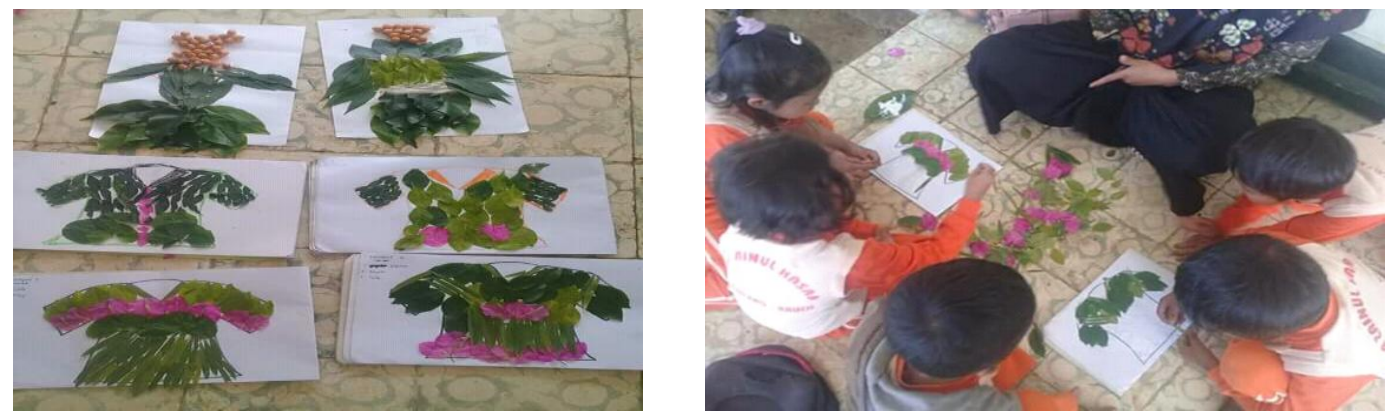

\section{Gambar 3: Pembelajaran Menempel}

Gambar di atas menunjukkan bahwa kegiatan pembelajaran sentra berupaya untuk mengakrabkan siswa dengan alam. Dalam hal ini guru membawa media yang akan digunakan untuk praktek pembelajaran yang mengarah pada peningkatan kecerdasan kognitif anak.

\section{Evaluasi Sentra}

Evaluasi dilakukan untuk mengetahui efektivitas dan efisiensi pembelajaran yang telah dilakukan oleh guru. Dalam kegiatan evalusi ini, guru melakukan penilaian dengan memperhatikan aspek authentic assessment. Hal ini sebagaimana disampaikan oleh Siti Rahayu bahwa "saya menilai siswa setelah selesai melakukan pembelajaran. Penilaian dilakukan dengan melihat berbagai perkembangan yang dicapai oleh anak, seperti perkembang agama dan moral, fisik motorik, kognitif, sosial emosional, bahasa, seni, keaktifan anak dalam menerima pelajaran yang diberika guru sangat berpengaruh pada tingkat perkembangan yang dicapai.

Di sini guru mengontrol perkembanagn peserta didiknya, mengingat setiap anak pasti berbeda tingkat kemampuan yang dicapai, sesuai daya ingat dan daya nalar pada masing-masing anak. Biasanya yang mudah terlihat pada aspek perkembagan anak adalah respon anak terhadap pelajaran yang diberikan oleh guru, anak akan terlihat sangat aktif bertanya dan menjawab setiap pertanyaan yang diajukan guru, sering berkomunikasi dengan teman di sebelahnya untuk memecahkan suatu masalah, guru menyuruh anak menceritakan kembali hasil karya yang dibuatnya, guru menanyakan kembali tentang hasil karyanya dari hasil observasi di lapangan.

Dari hasil observasi peneliti di lapangan, didapatkan bahwa guru di Raudlatul Athfal Zainul Hasan dalam system penelitiannya berusaha untuk mengembangkan enam aspek, yang dapat dilihat pada tabel berikut; 
Tabel 1 : Aspek Perkembangan Anak

\begin{tabular}{|c|c|}
\hline ASPEK PERKEMBANGAN & PENCAPAIAN PERKEMBANGAN \\
\hline Nilai agama dan moral & $\begin{array}{l}\text { Membaca do'a sebelum dan seselai pelajaran, } \\
\text { dan bertanggung jawab atas tugas yang } \\
\text { diberikan }\end{array}$ \\
\hline Fisik Motorik & $\begin{array}{l}\text { Menggunting daun dengan baik dan } \\
\text { rapi,menempel daun sesuai gambar yg } \\
\text { diberikan guru } \\
\text { Anak dapat menyebutkan beberapa jenis daun } \\
\text { dan bunga. }\end{array}$ \\
\hline Kognitif & $\begin{array}{l}\text { Mengelompokkan benda sesuai jenisnya, } \\
\text { seperti daun, bunga dan lain-lain, serta } \\
\text { menghitung dan mengelompokkan sesuai } \\
\text { warnanya. }\end{array}$ \\
\hline Sosial emosional & $\begin{array}{l}\text { Bekerja sama dengan baik untuk menempel } \\
\text { gambar bersama kelompok, dan bersabar } \\
\text { menunggu giliran untuk menempel. }\end{array}$ \\
\hline Bahasa & $\begin{array}{l}\text { Dapat menjalankan perintah guru dan } \\
\text { bertanggung jawab, mampu menjawab } \\
\text { pertanyaan guru dan mampu menyebutkan } \\
\text { nama-nama benda yang ditempel }\end{array}$ \\
\hline Seni & $\begin{array}{l}\text { Menempel sesuai gambar yang diperintahkan } \\
\text { guru dengan baik dan benar serta dapat } \\
\text { bernyanyi sesuai tema alam. }\end{array}$ \\
\hline
\end{tabular}

Dari table tersebut di atas, dapat diketahui bahwa penilaian pembelajaran berbasis sentra alam yang dilakukan oleh guru di Raudlatul Athfal Zainul Hasan menggunakan enam aspek penilaian dalam tiap hari. Hal ini ditujukan untuk mengukur perkembangan peserta didik dalam kegiatan pembelajarannya berbasis sentra alam.

\section{KESIMPULAN}

Pengelolaan pembelajaran sentra alam pada anak usia dini dalam meningkatkan kecerdasan kongnitif anak dilakukan secara terencana dan sistematis oleh guru di Raudlatul Athfal Zainul Hasan, Desa Tambelang, Kecamatan Krucil, Kabupaten Probolinggo. Pengelolaan tersebut meliputi pembuatan perencanaan yang dilakukan oleh guru melalui pembutaan RKH, kemudian dilanjutkan dengan implementasi perencanaan $\mathrm{RKH}$ dan diakhiri dengan evaluasi berbasis authentic assessment yang dilakukan dengan mengacu pada continuous improvement.

Penelitian ini memberikan implikasi pada pentingnya pengelolaan pembelajaran yang harus dilakukan oleh guru untuk mendapatkan hasil pembelajaran yang maksimal dan sesuai yang diharapkan. Melalui pengelolaan pembelajaran yang sistematis, guru dapat mengetahui sejauh mana ketercapaian pembelajaran yang telah dilakukannya guna ditindak lanjuti dengan perbaikan-perbaikan. 
Alfatihaturrohmah, A., Mayangsari, D., \& Karim, M. B. (2018). Kemampuan Berbicara Anak Usia 5-6 Tahun di TK X Kamal. Jurnal Pendidikan Dan Pembelajaran Anak Usia Dini2, 5(2), 101-109.

Alfina, A., \& Anwar, R. N. (2020). Manajemen Sekolah Ramah Anak Paud Inklusi. Al-Tanzim: Jurnal Manajemen Pendidikan Islam, 4(1), 36-47. https://doi.org/10.33650/al-tanzim.v4i1.975

Almuhajir, A. (2021). Controlling the Muhammadiyah Lhokseumawe Orphanage in Forming Independent Character of Foster Children. AlTanzim: Jurnal Manajemen Pendidikan Islam, 5(1), 176-189. https://doi.org/10.33650/al-tanzim.v5i1.1962

Arif, D., \& Pratama, N. (2019). Tantangan Karakter di Era Revolusi Industri dalam Membentuk Kepribadian Muslim. Al-Tanzim: Jurnal Manajemen Pendidikan Islam, 3(1), 198-226.

Atika, Arifin, Z., \& Jannana, N. S. (2021). Integrated School ManagementCharacter Education Affirmation: A Case Study in Muhammadiyah Wirobrajan 3 Elementary. Al-Tanzim: Jurnal Manajemen Pendidikan Islam, 5(2), 15-26.

Erwani. (2017). Meningkatkan Kemampuan Kognitif melalui Modifikasi Pembelajaran Sentra di RA Nurul Ida Kecamatan Gebang Kabupaten Langkat. Jurnal PGSD UNIMED, 1(1), 86-92.

Fatmawati, F. (2019). Meningkatkan Kretivitas Anak Melalui Kegiatan Bermain pada Pembelajaran Sentra Persiapan di TK Kemala Bhayangkari 29 Kota Jambi. Jurnal Literasiologi2, 2(1), 19-19.

Iltiqoiyah, L. (2020). Manajemen Pembelajaran melalui Pendekatan BCCT dalam Meningkatkan Multiple intelligences Anak. Jurnal Obsesi: Jurnal Pendidikan Anak Usia Dini, 5(2), 1368-1381. https://doi.org/10.31004/obsesi.v5i2.781

Maratus. (2016). Model Pembelajaran Sentra Balok Modifikasi Terhadap Kemampuan Kognitif Memahami Konsep Ukuran Pada Anak Autis di TK. Jurnal Pendidikan Khusus, 8(1), 1-12.

Mundiri, A., \& Adhimiy, S. (2019). Religious Authoritative Parenting Berbasis Quantum Meaningfullness of Life; Melejitkan Potensi Raih Prestasi. Probolinggo: Pustakan Nurja.

Nurhasanudin, \& Santika, T. (2021). Pendekatan Sentra Bermain Peran Untuk Meningkatkan Kecerdasan Sosial Emosional Anak Usia Dini. JoCE; Journal of Community Education, 2(1), 38-42.

Nurmiyanti, L., \& Candra, B. Y. (2019). Kepemimpinan Transformasional dalam Peningkatan Mutu Pendidikan Anak Usia Dini. Al-Tanzim: Jurnal Manajemen Pendidikan Islam, 3(2), 13-24. https://doi.org/10.33650/altanzim.v3i2.646

Purnomo, H., Chaer, M. T., \& Mansir, F. (2021). Humanistic Public Service Education in Government Gamping Sub-District Yogyakarta. Al-Tanzim: Jurnal Manajemen Pendidikan Islam, 5(2), 52-61.

Qori'ah. (2019). Model Pembelajaran Sentra Pada Anak Usia 4-5 Tahun. Kumara Cendekia, 7(1), 89-103. 
Sunanik, S. (2018). Pembelajaran Berbasis Alam Untuk Anak Usia Dini di TK Alam Alazhar Kutai Kartanegara. Al-Madrasah: Jurnal Pendidikan Madrasah Ibtidaiyah, 3(1), 82-110.

Sutisnawati, E., Mulyana, E. H., \& Sumardi, S. (2020). Keterampilan Saintifik Anak Kelompok A Pada Permainan Sains di Sentra Bahan Alam RA Baiturrahman. Jurnal Pendidikan Dan Konseling (JPDK), 1(2), 32-39.

Tatminingsih, S. (2019). Alternatif Stimulasi Kemampuan Kognitif melalui Penerapan Model Pembelajaran Berbasis Permainan Komprehensif. Jurnal Obsesi: Jurnal Pendidikan Anak Usia Dini, 3(1), 183. https://doi.org/10.31004/obsesi.v3i1.130

Watini, S. (2019). Implementasi Model Pembelajaran Sentra pada TK Labschool STAI Bani Saleh Bekasi. Jurnal Obsesi: Jurnal Pendidikan Anak Usia Dini, $4(1), 110-123$.

Widayati, L., Hidayat, S., \& Makmuri, M. (2018). Implementasi Skill Melipat, Menarik Garis dan Menuang Biji dapat Meningkatkan Motorik Halus Anak Usia Dini di RA Dewi Masyithoh Muslimat NU Kecamatan Puger Kabupaten Jember. Journal of Education Technology and Inovation, 1(2), 3446.

Zuarida. (2020). Penerapan Model Pembelajaran Sentra Multimedia Pada Kelompok B di TK Raudlatul Jannah Waru Sidoarjo. PAUD Teratai, 9(1), $1-8$. 